\title{
Impacts of long-term ragweed pollen load and other potential risk factors on ragweed pollen allergy among schoolchildren in Hungary
}

\author{
Krisztina Vörös ${ }^{1, C-D}$, János Bobvos ${ }^{2, A, E}$, János Mihály Varró ${ }^{3, C}$, Tibor Málnásii, ${ }^{4, B}$, Tamás Kói ${ }^{5, C}$, \\ Donát Magyar, ${ }^{6, B}$, Péter Rudnai ${ }^{7, A, E-F}$, Anna Páldy ${ }^{2, A, E-F}$ \\ ${ }^{1}$ Doctoral School of Pathological Sciences, Semmelweis University, School of Ph.D. studies, Pathological Sciences, \\ Budapest, Hungary \\ ${ }^{2}$ National Institute of Public Health, Department of Climate Change and Health Effect, Budapest, Hungary \\ ${ }^{3}$ Free lancer in biostatistical area, Ócsa, Hungary \\ ${ }^{4}$ National Institute of Public Health, Public Health Directorate, Budapest, Hungary \\ ${ }^{5}$ Budapest University of Technology and Economics, Institute of Mathematics, Budapest, Hungary \\ ${ }^{6}$ National Institute of Public Health, Department of Air Hygiene and Aerobiology, Budapest, Hungary \\ ${ }^{7}$ National Institute of Public Health, Department of Environmental Epidemiology, Budapest, Hungary \\ A - Research concept and design, B - Collection and/or assembly of data, C - Data analysis and interpretation, \\ $D$ - Writing the article, E - Critical revision of the article, F - Final approval of article.
}

Vörös K, Bobvos J, Mihály Varró J, Málnási T, Kói T, Magyar D, Rudnai P, Páldy A. Impacts of long-term ragweed pollen load and other potential risk factors on ragweed pollen allergy among schoolchildren in Hungary. Ann Agric Environ Med. 2018; 25(2): 307-313. doi: 10.26444/aaem/82624

\begin{abstract}
Introduction and objective. Hungary is one of the areas in Europe most infected with ragweed (Ambrosia artemisiifolia L.) and its pollen, and is the most important cause of seasonal allergic rhinoconjunctivitis in the country. The aim of the study was to investigate the association between ragweed pollen allergy and long-term ragweed pollen load, as well as analysis of the the impacts of additional potential risk factors on health outcomes.

Materials and method. A modified version of standardized questionnaires, based on the International Study of Asthma and Allergy in Childhood, were completed by the parents of schoolchildren aged 8 - 9 attending 3rd grade classes throughout the country. Pollen load was calculated for each settlement from daily ragweed pollen concentrations monitored by 19 monitoring stations in the country. Descriptive and analytical statistical methods were applied.

Results. At national level there was a significant inverse association between prevalence of ragweed allergy and its pollen load, but significance was lost after excluding data from Budapest, the capital city, due to the impact of urbanization. In the adjusted model, parental atopic disease was the strongest risk factor (either parent had atopic disease aOR=2.60; 95\% $\mathrm{Cl}=2.31-2.93$ or both parents had atopic disease $\mathrm{aOR}=4.56 ; 95 \% \mathrm{Cl}=3.71-5.60)$. Further significant risk factors were male gender $(\mathrm{aOR}=1.52 ; 95 \% \mathrm{Cl}=1.36-1.71)$, lower respiratory infection in the first two years of life $(\mathrm{aOR}=1.91 ; 95 \% \mathrm{Cl}=1.70-2.16)$, and unshared children's room ( $\mathrm{aOR}=1.22 ; 95 \% \mathrm{Cl}=1.09-1.37)$. Allergy was significantly less common among children whose parents received social aid $(\mathrm{aOR}=0.83 ; 95 \% \mathrm{Cl}=0.72-0.97)$ and whose mother smoked during pregnancy $(\mathrm{aOR}=0.80 ; 95 \%$ $\mathrm{Cl}=0.64-0.99$ ).
\end{abstract}

Conclusions. Higher ragweed pollen exposure was not found to be associated with higher risk of ragweed allergy.

Key words

children, infection, risk factor, prevalence, pollen load, common ragweed

\section{INTRODUCTION}

Hungary is one of the most infected areas with ragweed (Ambrosia artemisiifolia L.) in Europe. Ragweed pollen allergy is a major public health concern in this country, affecting almost $25 \%$ of Hungarian inhabitants [1]. Since the early 1990s, A. artemisiifolia has spread in Hungary and by 1997 had become the primary and the most important weed, and during the last decade the pollen of common ragweed has become the main cause of pollinosis [2]. A previous Hungarian study found that skin prick test positivity to ragweed reached more than $80 \%$ among adult patients with symptoms of seasonal allergic rhinitis and who lived in the

Address for correspondence: Krisztina Vörös, Doctoral School of Pathological Sciences., Semmelweis University, School of Ph.D. studies, Pathological Sciences, Üllői út 26,1085, Budapest, Hungary, Sporttelep utca 13, 1046 Budapest, Hungary e-mail: kriszvor5@gmail.com

Received: 24.04.2017; accepted: 11.01.2018; first published: 07.03.2018 southern parts of the country [3]. In Budapest, ragweed was responsible for the allergic symptoms in 59\% of children suffering from pollen allergy [4]. Since the $19^{\text {th }}$ century, hay fever has been considered a disease of the wealthy [5] and several studies reported a higher prevalence of allergic rhinoconjuntivitis among people with higher social status [6]. The relationship between pollen exposure and occurrence of allergic rhinitis remains less clear $[7,8]$.

\section{OBJECTIVE}

The aim of this study was to investigate the associations between long-term ragweed pollen load and lifetime prevalence of ragweed allergy in Hungary, and to analyse what other factors may have impact on the risk of allergy, especially the socio-economic status of the family, as well as environmental factors during early life. 


\section{MATERIALS AND METHOD}

Study design and participations. In autumn 2005, the National Institute of Environmental Health carried out a country-wide cross-sectional study using a modified version of standardized questionnaires from the International Study of Asthma and Allergies in Childhood [9] to estimate the prevalence of allergic, asthmatic and chronic respiratory symptoms and their possible risk factors among 8-9-year-old schoolchildren attending $3^{\text {rd }}$ grade classes throughout the country. The core questions were translated into Hungarian and supplemented with additional questions concerning allergy, especially to ragweed, and its possible risk factors. Questionnaires were sent to every school in the country where at least 10 children attended the $3^{\text {rd }}$ class. The questionnaires were completed by the parents anonymously and only data related to ragweed pollen allergy were analysed.

Questionnaire: ragweed allergy diagnosis and independent factors. The lifetime prevalence of 'diagnosed ragweed pollen allergy', henceforth 'ragweed allergy', was determined from the responses to the question: 'Has your child ever been diagnosed with ragweed pollen allergy by a doctor?' There were also questions related to symptoms of hay fever in the past six months. On the one hand these questions provided information about the prevalence of hay fever only in the previous season and not about lifetime prevalence; on the other hand, confounders of any other weed blooming in the same period as ragweed could not be filtered out. Therefore, these questions were excluded from the analysis. Information about family history, birth and early childhood circumstances, socio-economic status of family and other covariates were taken from the questionnaires and analysed in relation to the risk of health outcomes:

- gender;

- age;

- family history: parental atopic disease (parental allergic and/or asthma disease);

- birth and early childhood circumstances: smoking regularly during pregnancy, maternal age at baby's birth, serious lower respiratory tract infection in the first two years of life (bronchitis, bronchiolitis or pneumonia), children's own unshared room;

- socio-economic status of family: receiving social aid.

At least one cigarette per day during pregnancy was considered as regular smoking. Maternal age (years) at baby's birth was categorized into five groups: $<20 ; 20-24.9 ; 25-29.9$; $30-34.9$; $\geq 35$ years. Serious lower respiratory tract infection requiring antibiotics were investigated, and this index was for using antibiotics in early life.

- Population size of settlements was also analysed as a covariate factor.

The data for permanent population of settlements in 2005 was provided by the Hungarian Central Statistical Office. The following categories were created: $\leq 5,000 ; 5,001-50,000$; $\geq 50,001$ inhabitants. The population of the capital Budapest $(1,690,109)$ was grouped into these categories in each district.

Monitoring and analysis of pollen data. The airborne pollen concentration of ragweed was monitored by 19 monitoring stations of the National Aerobiological Network operating according to international standards. Air samples were continuously collected by Hirst-type pollen traps (Burkard Manufacturing Co. Ltd., Rickmansworth, UK) [10]. The pollen grains were collected on a plastic tape with its surface covered with adhesive material. The exposed tape was located in a rotating drum, changed weekly, and cut into daily segments on a microscope slide. Each slide had a scale per two hours and was stained with glycerine jelly containing basic fuchsine, and read by using an optical microscope at $\times 400$ magnification [11]. Data are expressed as the sum of the twohour pollen counts from $0-24$ hours (pollen grains $/ \mathrm{m}^{3} /$ day).

Long-term ragweed pollen load of settlements. The average sum of ragweed pollen concentration was calculated from the summarized daily pollen level per each year; these values were then averaged for the period $1999-2005$ by each monitoring station. Missing values due to pollen trap error during the examined period were obtained by the following procedure: annual country averages were calculated from the annual concentrations of ragweed pollen at monitoring stations with no missing data, these values were then included into linear regression with annual data of each station with missing values. The missing values were replaced by the country average using the estimated intercept and slope for each station. The long-term (1999-2005) average pollen load for each settlement in Hungary and for 23 districts of Budapest was calculated, averaging the weighted pollen load of each monitoring station as follows: the pollen load of each station was multiplied by the inverse of the square of the distance (measured in $\mathrm{kms}$ ) of each settlement from each pollen monitoring station. The pollen exposures by settlements were added to the database containing the children's individual parameters based on the responses to the questionnaires. The pollen exposure was assessed as the explanatory variable for the health outcome after inputting the same pollen value for every child living in the same settlement.

Statistical analysis. Children who had changed their place of residence since birth were excluded from the analysis, as well as children aged 10 years or older. The study was further restricted to children with information on health outcome and all the factors studied. For statistical and development purposes, Hungary is divided into seven regions by the Nomenclature of Territorial Units for Statistics, level 2 (NUTS2) developed by Eurostat. The prevalence of ragweed allergy and pollen load was presented for the whole country and in each region by NUTS2, as well as Budapest, respectively. The long-term ragweed pollen load was investigated both as a continuous explanatory variable and a categorical variable. Regards the whole country, the pollen load was divided into equal parts, as far as possible taking into account an adequate number of cases belonging to each category. Thus, five concentration categories $(1,501-3,500$; 3,501-5,500; 5,501-7,500; 7,501-9,500; 9,501-13,000 pollen grains $/ \mathrm{m}^{3}$ ) were created. In the case of Budapest, different categories of pollen load were created due to the lower levels of concentration $(3,250-3,349 ; 3,350-3,449 ; 3,450-3,549 ; 3,550-$ 3,$649 ; 3,650-3,749$ pollen grains $\left./ \mathrm{m}^{3}\right)$. Descriptive statistical methods were used to demonstrate prevalence data, and Chi-square tests were applied to compare frequencies. The differences in pollen load between the residence of children with or without diagnosed ragweed allergy were tested by the Mann-Whitney U test. This test was also applied for 
determining whether there were differences in pollen load, on the one hand between Budapest and the rest of the country without Budapest, and on the other hand, between two categories of population size. Associations between health outcomes and potential risk factors were assessed using binary logistic regression analyses, by also following the procedure in the analysis restricted to the whole country and separately from data on Budapest due to the impact of urbanisation. First, all independent variables were included in the regression, after which the analysis was performed again while omitting the non-significant variables step-bystep. Pollen load categories and the factors with significant relationship with ragweed allergy were presented in the final model. Crude odds ratio (cOR) and adjusted odds ratio (aOR) with their 95\% confidence intervals (95\% CI) were presented as results for each factor in the final model. Factors omitted from regression analysis were not represented in the final model; therefore, there was no single confounder participating in the multivariate analysis without presenting aOR in the final model. $\mathrm{P}$ value was considered to be statistically significant at $<0.05$. Statistical analyses were performed using IBM SPSS version 23.0. ArcGIS software was applied for showing the distribution of ragweed allergy by NUTS2 regions.

Ethical consideration. The survey was carried out following approval by the Ministerial Commissioner for Data Protection (261/K/2005), and on receipt of written informed consent from the parents of the participants.

\section{RESULTS}

Panel participation and description. 62,711 questionnaires were completed by the parents with a $76.4 \%$ response rate, and returned to the schools throughout the whole country. Data from 60,015 questionnaires were analysed after excluding those that could not be interpreted. The place of residence of about every second child had changed since their birth, these children and the questionnaire not meeting the inclusion criteria, were therefore excluded from the analysis. Finally, a total of 20,482 children were included in the study. Table 1 presents the general characteristics of the study population.

Distribution of prevalence of ragweed allergy and pollen data. There were highly significant differences $(p<0.001)$ in the prevalence of ragweed allergy among the seven regions of the country (Fig. 1). The countrywide average was $6.5 \%$. Budapest, situated in Central Hungary, was examined separately due to the impact of urbanisation on the capital city. The prevalence of ragweed allergy in Budapest was $9.4 \%$, which was significantly higher $(\mathrm{p}<0.001)$ than the other regions in the country; the long-term pollen load, however, was significantly lower $(p<0.001)$ than in the rest of the country (Tab. 2). In the smallest settlement category, the prevalence of ragweed allergy was 5.9\%, and in settlements with 5,001-50,000 inhabitants was $6.2 \%$. The prevalence of allergy was significantly higher only in the largest settlement category $(8.0 \%$ at country level; $7.1 \%$ in the rest of the country, excluding Budapest), compared to the baseline category (settlements with $\leq 5,000$ inhabitants). There were significantly $(\mathrm{p}<0.001)$ decreased levels of pollen load in both categories of population size related to the $\leq 5,000$
Table 1. General characteristics of studied schoolchildren at country level and in Budapest, respectively, in Hungary, 2005

\begin{tabular}{|c|c|c|}
\hline & at country level & in Budapest \\
\hline Variables & $\mathrm{N}(\%)$ & n (\%) \\
\hline male & $10,049(49.1)$ & $939(51.5)$ \\
\hline female & $10,433(50.9)$ & $886(48.5)$ \\
\hline 8 years old & $7,371(36.0)$ & $503(27.6)$ \\
\hline 9 years old & $13,111(64.0)$ & $1,322(72.4)$ \\
\hline \multicolumn{3}{|l|}{ parental allergic and/or asthma disease } \\
\hline no parental disease & $14,815(72.3)$ & $1,167(63.9)$ \\
\hline either parent had a disease & $4,932(24.1)$ & $542(29.7)$ \\
\hline both parents had a disease & 735 (3.6) & $116(6.4)$ \\
\hline \multicolumn{3}{|l|}{ maternal age at baby's birth (years) } \\
\hline$<20$ & $849(4.1)$ & $59(3.2)$ \\
\hline $20-24.9$ & $5,898(28.8)$ & $364(20.0)$ \\
\hline $25-29.9$ & $7,857(38.4)$ & $701(38.4)$ \\
\hline $30-34.9$ & $3,837(18.7)$ & $463(25.4)$ \\
\hline$\geq 35$ & $2,041(10.0)$ & $238(13.0)$ \\
\hline smoking during pregnancy & $2,092(10.2)$ & $184(10.1)$ \\
\hline $\begin{array}{l}\text { lower respiratory tract infection in the first two } \\
\text { years of life }\end{array}$ & $4,559(22.3)$ & $383(21.0)$ \\
\hline unshared, own children's room & $10,186(49.7)$ & $854(46.8)$ \\
\hline receiving social aid & $4,746(23.2)$ & $228(12.5)$ \\
\hline \multicolumn{3}{|l|}{ population size of settlements } \\
\hline$\leq 5,000$ & $7,660(37.4)$ & - \\
\hline $5,001-50,000$ & 8,030 (39.2) & $87(4.8)$ \\
\hline$\geq 50,001$ & 4,792 (23.4) & $1,738(95.2)$ \\
\hline \multicolumn{3}{|l|}{ regions } \\
\hline Western Transdanubia & $2,071(10.1)$ & \\
\hline Central Transdanubia & $2,282(11.1)$ & \\
\hline Southern Transdanubia & $1,834(9.0)$ & \\
\hline Central Hungary & $4,308(21.0)$ & \\
\hline Northern Hungary & $2,878(14.1)$ & \\
\hline Northern Great Plain & 3,933 (19.2) & \\
\hline Southern Great Plain & $3,176(15.5)$ & \\
\hline Total & $20,482(100)$ & $1,825(100)$ \\
\hline
\end{tabular}

Data are shown as number (\%) of children

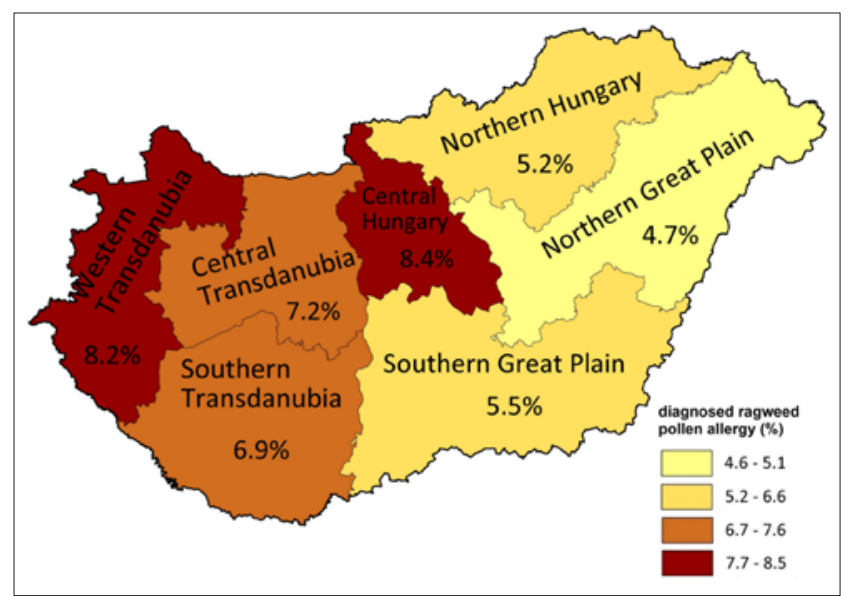

Figure 1. Prevalence of the diagnosed ragweed pollen allergy among 8-9 year old schoolchildren attending $3^{\text {rd }}$ grade classes based on parents-administered questionnaire by NUTS2 regions, Hungary, 2005 
Table 2. Characteristics of pollen load by NUTS2 regions, country level, rest of the country without Budapest and Budapest separately, 1999-2005 (pollen grains $/ \mathrm{m}^{3}$ )

\begin{tabular}{lcccccc}
\hline Regions & min & $\mathbf{2 5} \mathbf{~ p c}$ & $\mathbf{5 0 p c}$ & $\mathbf{7 5 p c}$ & $\mathbf{m a x}$ & mean (S.E.) \\
\hline Western Transdanubia & 2,880 & 3,486 & 4,335 & 5,712 & 7,008 & $4,544(27)$ \\
\hline Central Transdanubia & 3,600 & 4,067 & 5,160 & 6,072 & 11,240 & $5,120(22)$ \\
\hline Southern Transdanubia & 6,221 & 6,576 & 6,727 & 6,809 & 7,518 & $6,730(6)$ \\
\hline Central Hungary & 3,296 & 3,545 & 3,813 & 4,151 & 10,177 & $4,111(16)$ \\
\hline Northern Hungary & 1,640 & 3,161 & 3,498 & 4,155 & 8,618 & $3,802(25)$ \\
\hline Northern Great Plain & 2,974 & 6,083 & 7,703 & 8,776 & 11,265 & $7,522(33)$ \\
\hline Southern Great Plain & 3,764 & 5,431 & 6,530 & 6,919 & 12,635 & $6,759(34)$ \\
\hline Country total & 1,640 & 3,823 & 5,160 & 6,729 & 12,635 & $5,524(14)$ \\
\hline $\begin{array}{l}\text { Rest of the country } \\
\text { without Budapest }\end{array}$ & 1,640 & 4,038 & 5,476 & 6,795 & 12,635 & $5,723(15)$ \\
\hline Budapest & 3,296 & 3,378 & 3,528 & 3,589 & 3,735 & $3,492(3)$ \\
\hline
\end{tabular}

category in the analysis at country level. The pollen load level was significantly lower in settlements with 5,001-50,000 inhabitants, but not significantly higher in settlements with $\geq 50,001$ inhabitants, related to the baseline category after excluding Budapest from the analysis (Fig. 2).

Pollen load in residence of children with and without allergy. The difference in pollen load between residences of children with or without ragweed allergy was significant $(\mathrm{p}<0.001)$ at country level, but not significant $(\mathrm{p}=0.067)$ after excluding the children living in Budapest. Analysing only children living in Budapest there was no significant $(p=0.071)$ difference in pollen load between districts of the city with allergic children and those who were non-allergic ones (Tab. 3).

Results of logistic regression analyses. The impacts of potential risk factors on chances of ragweed allergy was analysed by binary logistic regression model at country level, excluding data of children living in Budapest, and separately for children living in Budapest (Tab. 4, 5). In both analyses, all the confounders with aOR were presented in the Tables. The univariate analysis at country level revealed only one $\left(7,501-9,500\right.$ pollen grains $\left./ \mathrm{m}^{3}\right)$ category, in relation to the baseline category $\left(1,501-3,500\right.$ pollen grains $\left./ \mathrm{m}^{3}\right)$, which showed a significant and inverse association with risk of
Table 3. Pollen load of residences of children with and without ragweed allergy at country level, in rest of the country without Budapest and in Budapest, separately, 1999-2005 (pollen grains $/ \mathrm{m}^{3}$ )

\begin{tabular}{lcccccc}
\hline \multirow{2}{*}{ Pollen load } & \multicolumn{2}{c}{ At country level } & \multicolumn{2}{c}{ without Budapest } & \multicolumn{2}{c}{ only in Budapest } \\
\cline { 2 - 7 } & Group I & Group II & Group I & Group II & Group I & Group II \\
\hline $\min$ & 1,640 & 1,640 & 1,640 & 1,640 & 3,296 & 3,296 \\
\hline $25 \mathrm{pc}$ & 3,698 & 3,848 & 3,972 & 4,041 & 3,378 & 3,375 \\
\hline $50 \mathrm{pc}$ & 4,794 & 5,191 & 5,441 & 5,476 & 3,543 & 3,528 \\
\hline $75 \mathrm{pc}$ & 6,691 & 6,733 & 6,739 & 6,798 & 3,596 & 3,589 \\
\hline $\max$ & 12,635 & 12,635 & 12,635 & 12,635 & 3,735 & 3,735 \\
\hline
\end{tabular}

mean (S.E.) $\quad 5,367(56) \quad 5,535(15) \quad 5,642(61) \quad 5,728(16) \quad 3,505(10) \quad 3,491(3)$

$\min =$ minimum; $\max =$ maximum; $\mathrm{pc}=$ percentiles

Group I - residences of children with ragweed allergy

Group II - residences of children without ragweed allergy

allergy. This association remained significant but became weaker after adjusting for the other factors. In the analysis excluding Budapest, the same category $(7,501-9,500$ pollen grains $/ \mathrm{m}^{3}$ ) was significantly associated with a decreased risk of allergy in the univariate analysis, but the significance faded away after adjustment for the other factors. In Budapest, a higher level of pollen load related to the baseline category $\left(3,250-3,349\right.$ pollen grains $\left./ \mathrm{m}^{3}\right)$ showed a non-significant and positive association with risk of allergy in both the univariate and adjusted models. In the univariate analysis, only the $\geq 50,001$ population size category was significantly associated with increased prevalence of allergy related to the baseline category ( $\leq 5,000$ inhabitants), both in the examination at country level $(\mathrm{cOR}=1.38 ; 95 \% \mathrm{CI} 1.20-1.59, \mathrm{p}<0.001)$, and also in the analysis without the data for Budapest $(\mathrm{cOR}=1.21$; $95 \%$ CI 1.02-1.43, p=0.025). Population size of settlements lost significance after adjustment for the other factors, indicating the effects of urban or rural environment already included in the effects of other factors.

Based on analysis of all data, excluding Budapest, parental atopic diseases were the strongest factors for risk of allergy. Serious lower respiratory tract infection in the first two years of life and unshared children's room were also risk factors. Ragweed allergy was significantly more common among boys than girls. Receiving social aid was inversely associated with the prevalence of health outcome. In analyses at country level, there was a decreased risk in the prevalence of allergy among children with mothers who smoked during

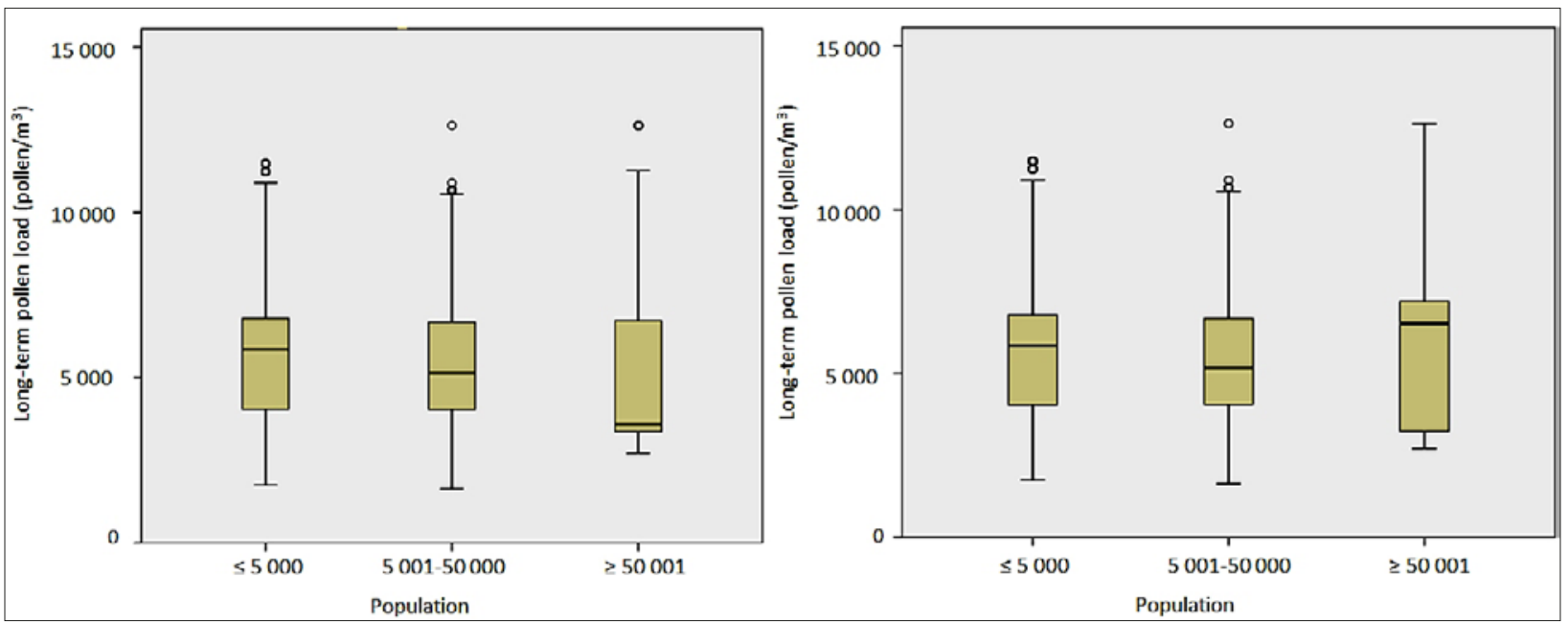

Figure 2. Pollen load levels of settlements of various population size at country level (left) and in rest of the country without Budapest (right), Hungary, 2005 
Table 4. Crude (cOR) and adjusted odds ratio (aOR) with $95 \% \mathrm{Cl}$ of pollen load categories and factors showing significant association with outcome in analysis at country level, without data for Budapest

\begin{tabular}{|c|c|c|c|c|c|c|c|c|}
\hline \multirow{2}{*}{ Factors } & \multicolumn{3}{|c|}{ Country level } & \multicolumn{5}{|c|}{ rest of the country without Budapest } \\
\hline & cOR $(95 \% \mathrm{Cl})$ & $p$ value & $\mathrm{aOR}^{*}(95 \% \mathrm{Cl})$ & $\mathrm{p}$ value & $\operatorname{cOR}(95 \% \mathrm{Cl})$ & $p$ value & $\mathrm{aOR}^{*}(95 \% \mathrm{Cl})$ & $p$ value \\
\hline male & $1.62(1.44-1.81)$ & $<0.001$ & $1.52(1.36-1.71)$ & $<0.001$ & $1.62(1.44-1.83)$ & $<0.001$ & $1.54(1.36-1.74)$ & $<0.001$ \\
\hline 9-years-old & $1.55(1.37-1.75)$ & $<0.001$ & $1.48(1.30-1.68)$ & $<0.001$ & $1.51(1.32-1.72)$ & $<0.001$ & $1.44(1.26-1.64)$ & $<0.001$ \\
\hline either parent had atopic disease & $2.74(2.43-3.08)$ & $<0.001$ & $2.60(2.31-2.93)$ & $<0.001$ & $2.71(2.39-3.08)$ & $<0.001$ & $2.60(2.28-2.94)$ & $<0.001$ \\
\hline both parents had atopic disease & $5.02(4.10-6.14)$ & $<0.001$ & $4.56(3.71-5.60)$ & $<0.001$ & $4.53(3.61-5.68)$ & $<0.001$ & $4.11(3.26-5.18)$ & $<0.001$ \\
\hline lower respiratory tract infection & $2.09(1.86-2.35)$ & $<0.001$ & $1.91(1.70-2.16)$ & $<0.001$ & $2.21(1.95-2.50)$ & $<0.001$ & $2.02(1.78-2.30)$ & $<0.001$ \\
\hline unshared children's room & $1.25(1.12-1.40)$ & $<0.001$ & $1.22(1.09-1.37)$ & 0.001 & $1.30(1.15-1.47)$ & $<0.001$ & $1.29(1.14-1.46)$ & $<0.001$ \\
\hline receiving social aid & $0.73(0.63-0.84)$ & $<0.001$ & $0.83(0.72-0.97)$ & 0.018 & $0.76(0.65-0.88)$ & $<0.001$ & $0.85(0.73-0.99)$ & 0.034 \\
\hline $3,501-5,500$ (pollen grains $/ \mathrm{m}^{3}$ ) & $0.95(0.80-1.12)$ & 0.513 & $0.95(0.80-1.13)$ & 0.563 & $0.99(0.81-1.20)$ & 0.897 & $0.97(0.79-1.19)$ & 0.773 \\
\hline $5,501-7,500$ (pollen grains $/ \mathrm{m}^{3}$ ) & $0.93(0.78-1.11)$ & 0.421 & $0.99(0.83-1.18)$ & 0.906 & $1.04(0.85-1.28)$ & 0.685 & $1.06(0.86-1.30)$ & 0.570 \\
\hline $9,501-13,000$ (pollen grains $/ \mathrm{m}^{3}$ ) & $0.88(0.66-1.18)$ & 0.410 & $0.88(0.65-1.18)$ & 0.385 & $0.99(0.73-1.35)$ & 0.951 & $0.94(0.68-1.29)$ & 0.689 \\
\hline
\end{tabular}

* odds ratios are adjusted for all factors in the Table, calculated relative to the baseline categories (gender=female; age=8-years-old; parental atopic diseases=No; maternal smoking during pregnancy $=\mathrm{No}$; lower respiratory infection $=\mathrm{No}$; unshared children's room=No, receiving social aid=No; pollen load= $1,501-3,500$ pollen grains $/ \mathrm{m}^{3}$ ). \# non significant results in final model.

Table 5. Crude (cOR) and adjusted (aOR) odds ratio with $95 \% \mathrm{Cl}$ of pollen load categories and factors showing significant association with health outcome in analysis with data only from Budapest

\begin{tabular}{lcccc}
\hline Factors & cOR $(95 \% \mathrm{Cl})$ & $\mathrm{p}$ value & aOR $(95 \% \mathrm{Cl})^{*}$ & p value \\
\hline male & $1.52(1.10-2.10)$ & 0.010 & $1.42(1.02-1.98)$ & 0.039 \\
\hline 9-years-old & $1.66(1.12-2.46)$ & 0.012 & $1.72(1.14-2.58)$ & 0.009 \\
\hline $\begin{array}{l}\text { either parent had } \\
\text { atopic disease }\end{array}$ & $2.73(1.92-3.87)$ & $<0.001$ & $2.70(1.89-3.84)$ & $<0.001$ \\
\hline $\begin{array}{l}\text { both parents had } \\
\text { atopic disease }\end{array}$ & $6.85(4.26-11.03)$ & $<0.001$ & $6.95(4.29-11.24)$ & $<0.001$ \\
\hline $3350-3449$ pollen $/ \mathrm{m}^{3}$ & $1.42(0.81-2.51)$ & 0.223 & $1.38(0.77-2.46)$ & 0.281 \\
\hline $3450-3549$ pollen $/ \mathrm{m}^{3}$ & $1.20(0.65-2.21)$ & 0.557 & $1.15(0.62-2.16)$ & 0.653 \\
\hline $3550-3649$ pollen $/ \mathrm{m}^{3}$ & $1.52(0.86-2.69)$ & 0.153 & $1.42(0.79-2.55)$ & 0.245 \\
\hline $3650-3749$ pollen $/ \mathrm{m}^{3}$ & $1.65(0.81-3.33)$ & 0.165 & $1.42(0.69-2.94)$ & 0.339 \\
\hline
\end{tabular}

* odds ratios are adjusted for all factors in the Table and are calculated relative to the baselin categories (gender $=$ female; age $=8$ years old; parental atopic disease $=$ no; pollen load $=3,250$ 3,490 pollen grains $/ \mathrm{m}^{3}$ )

pregnancy, compared with children whose mothers did not smoke during that time. The association remained inverse but not significant after excluding the children living in Budapest. Maternal age at baby's birth showed a nonsignificant association with allergy in both analysis. In contrast, in the analysis with the sub-group of only children living in Budapest, serious lower respiratory tract infection in the first two years of life, unshared children's room, and receiving social aid were not significantly associated with the prevalence of allergy. The association between smoking during pregnancy and risk of children's allergy was inverse and close to significant $(\mathrm{p}=0.051)$. Consistent with the results of the study at national level, excluding data from Budapest, maternal age at baby's birth did not show association with risk of health outcomes.

\section{DISCUSSION}

Ragweed pollen allergy is a major public health concern in Hungary with substantial differences in prevalence among regions. In this study, pollen exposure at settlement level was calculated in several ways. First, exposure of each settlement was characterized by the pollen exposure of the GIS determined nearest pollen station. In this case, systematic bias occurred in exposure of settlements in areas with nearly equal distance from two or more monitoring stations. Pollen exposure was then calculated by averaging the weighted pollen load of each monitoring station located at 500, 300 and 100/50 kms distance from the settlements, but the results of analysis did not improve. Therefore, pollen exposure of settlements was calculated from weighted data of all monitoring stations; this method smoothed the differences of exposure of the neighbouring settlements. The spatial distribution of pollen load was similar to the distribution of ragweed infested areas, based on the 2004 fenologic survey of Plant and Soil Protection Services [2]. Analysis at country level showed, that in parts of the country with a higher pollen load the prevalence of ragweed allergy was lower, but there was no longer a significant negative association between pollen load and risk of allergy after exclusion of Budapest data. As more than $43.6 \%$ of data of Budapest belonged to the baseline category $\left(1,501-3,500\right.$ pollen grains $\left./ \mathrm{m}^{3}\right)$ of pollen load and the prevalence of ragweed allergy was significantly higher than the average of the rest of the country without the capital, it was supposed that the relationship was significant due to the impacts of urbanisation of Budapest. Another possible explanation for the result of only one pollen load category being significant with the outcome in the regression model at national level, but no category in the analysis excluding Budapest, could be that the small differences can be statistically significant owing to the large number of samples [12]. Positive association has been demonstrated between the presence of ragweed and frequencies of both sensitization and allergy to ragweed in northern Italy [13] and in France [14], but not in another study from northern Italy [15].

Lower prevalence of allergy was observed in small settlements with less than 5,000 inhabitants, compared to settlements with a bigger population at country level, and excluding Budapest from the analysis. Lower prevalence in rural areas may also be explained by lower socio-economic status, lower level of air pollution, or more difficult accessibility to health care services. Epidemiologic studies showed 
decreased risk of hay fever and allergic sensitization among children living in rural areas compared with those living in an urban environment $[16,17]$. Substantial differences in the prevalence of ragweed allergy among regions may be driven by inequality in the socio-economic status. The lowest prevalence of ragweed allergy was detected in the socially more deprived areas [18] of Hungary.

Based on the presented results of children with parents receiving social aid, the odds for allergy were less common than in those whose parents did not receive social aid. The risk for allergy was significantly higher in children with own, unshared room, compared with children in a shared room. Lower standard of living, crowding, and low level of hygiene increased the chance for acquiring infections, and seem to be a protective factor against allergic diseases [19, 20, 21]. In the presented study, about two-thirds of the children (66.4\%) with parents receiving social aid did not have own, unshared children's room, thus they might have a greater chance for acquiring infections from members of their family.

After the reunification of Germany, a significantly increased prevalence of hay fever with significant change of some lifestyle factors was observed in former East Germany, compared with former West Germany, confirming the hygiene hypothesis [22]. Unlike in other studies, the protective effect of early infections with respect to the development of later allergic disease was not confirmed [23,24].

Several authors have demonstrated that the antibiotic therapy in early childhood was a risk factor for development of later allergic rhinitis [25]. In the results obtasined for the current study, the odds of ragweed allergy were higher in children who had serious lower respiratory tract infection (those required antibiotic therapy) in the first two years of life, compared to children without infection during that period. This result is in line with other studies showing that the risk of hay fever and other atopic disorders was higher among children receiving antibiotic therapy in the first two years of life [26]. Inadequate composition or depletion of intestinal microflora by antibiotics may partly be responsible for the development of atopic diseases. Kalliomäki et al. [27] showed different ratios of bifidobacteria to clostridia in the neonatal gut microflora between infants in whom atopy later developed, compared to those without atopy. Genetic predisposition is a determinant factor for developing allergic diseases. In the presented study, parental atopic disease was the strongest risk factor for allergy in all the three analyses. A Korean study reported that using antibiotics during infancy significantly increased the risk for allergic rhinitis in subjects with the CD14TT genotype, and the risk for atopic allergic rhinitis in those with the TLR4CC genotype, while in subjects with other genotypes the association was not significant [28].

In the current analysis there were no significant associations between maternal age at baby's birth and risk of allergy. In cohort studies, increasing maternal age was associated with significantly increased risk for hay fever in children [29]. However, the delivery mode, being an important factor of allergy risk [30], was not analysed. In the presented study, there was an inverse significant association between smoking during pregnancy and risk of ragweed allergy in children in the analysis at country level, but the significance faded away after excluding data of children living in Budapest. As the prevalence of smoking during pregnancy was nearly equal in Budapest and in the rest of the country without Budapest, it was supposed that the association was significant at country level due to the significantly higher prevalence of ragweed allergy in Budapest. Another explanation for inverse association may be that the impact of smoking during pregnancy is expressed by social state. Prevalence of smoking during pregnancy was significantly higher $(\mathrm{p}=0.000)$ among mothers receiving social aid, compared with those who did not receive social aid. Analysing only the data of children whose parents received social aid, the prevalence of ragweed allergy was not significantly higher $(\mathrm{p}=0,894)$ among children whose mother smoked, compared with those with nonsmoking mother during pregnancy. In a British study, a high level of maternal smoking during pregnancy was significantly associated with decreased odds of hay fever in children [31], but with higher odds for allergic sensitization only among children with parental atopy in a German study [32].

Examining only the children living in Budapest, the regression results differed from the analyses at country level and in the rest of the country without Budapest, which could be explained by the lower level of reliability due to a lower number of cases. Differences in the prevalence of ragweed allergy among regions and higher prevalence of allergy parallel with lower level of pollen load in Budapest, may also be due to higher level of chemical air pollution in the capital and in some parts of the country. A previous Hungarian study revealed that exposure to traffic density was significantly higher in urban than in rural children [33]. Traffic-related chemical air pollutants (mainly $\mathrm{PM}_{10}, \mathrm{SO}_{2}$, $\mathrm{NO}_{2}, \mathrm{O}_{3}$ ) may enhance the allergenic effects of pollen grains [34] and can raise the prevalence of allergic rhinitis [35].

Limitations of the study. Although the presented study is the first to be undertaken in Hungary to estimate the possible risk factors of ragweed pollen allergy at country level among children, there were some limitations to the study. The health outcome was considered based on responses to questionnaires completed by the parents, and there was no specific question about how the diagnosis was made. As this was a retrospective study, the inaccuracy of parental memory concerning information about their children at younger ages may have biased the results. Furthermore, there may have been differences in diagnostic procedures, accessibility, and quality of paediatric services, parental knowledge about symptoms of allergy and parental charge, thereby using or disregarding health services throughout the country, especially between affluent and deprived areas that could distort the results.

\section{CONCLUSIONS}

Higher pollen exposure was not found to be associated with higher risk of allergy. Considerable differences were observed in the prevalence of ragweed pollen allergy among different parts of the country, which could not be explained only by different levels of long-term pollen load. Beside genetic predisposition, inequality in socio-economic status are also determinants for the risk of allergy, but impacts of other factors, e.g. air pollution, pets, delivery mode, availability of health care services, may also influence the outcome. Therefore,, these factors should be examined in further studies. 


\section{REFERENCES}

1. Kazinczi G, Béres I, Pathy Z, Novák R. Common ragweed (Ambrosia artemisiifolia L.): a review with special regards to the results in Hungary: II. Importance and harmful effect, allergy, habitat, allelopathy and beneficial characteristics. Herbologia. 2008; 9(1): 93-118.

2. Novák R, Karamán J, Kazinczi G, Somodi I, Csecserits A, Kovács A, et al. The spreading of common ragweed. In: Kazinczi G, Novák R, editors. Integrated methods for suppression of common ragweed. National Food Chain Safety Office, Directorate of Plant Protection, Soil Conservation and Agri-environment, Budapest; 2014. p. 31-48.

3. Kadocsa E, Juhász M. Change of the allergen spectrum of hay fever patients in the South Great Plain of Hungary (1990-1998). Orvosi Hetilap. 2000; 141(29): 1617-20.

4. Mezei G, Járainé Komlódi M, Medzihradszky Z, Cserháti E. Seasonal allergic rhinitis and pollen count. Orvosi Hetilap. 1995; 136(32): 1721-24.

5. Emanuel MB. Hay fever, a post industrial revolution epidemic: a history of its growth during the 19th century. Clin Allergy. 1988; 18(3): 295-304.

6. Uphoff E, Cabieses B, Pinart M, Valdés M, Antó JM, Wright J. A systematic review of socioeconomic position in relation to asthma and allergic diseases. Eur Respir J. 2015; 46(2): 364-74.

7. Burr ML, Emberlin JC, Treu R, Cheng S, Pearce NE; ISAAC Phase One Study Group. Pollen counts in relation to the prevalence of allergic rhinoconjunctivitis, asthma and atopic eczema in the International Study of Asthma and Allergies in Childhood (ISAAC). Clin Exp Allergy. 2003; 33(12): 1675-80.

8. Charpin D, Hughes B, Mallea M, Sutra JP, Balansard G, Vervloet D. Seasonal allergic symptoms and their relation to pollen exposure in south-east France. Clin Exp Allergy. 1993; 23(5): 435-9.

9. Asher MI, Keil U, Anderson HR, Beasley R, Crane J, Martinez F, et al. International Study of Asthma and Allergies in Childhood (ISAAC): rationale and methods. Eur Respir J. 1995; 8(3): 483-491.

10. Hirst JM. An automatic volumetric spore trap. Ann App Biol. 1952; 39: 257-65.

11. Páldy A, Bobvos J, Fazekas B, Mányoki G, Málnási T, Magyar D. Characterisation of the pollen season by using climate specific pollen indicators. Cent Eur J Occ Envir Med. 2014; 20(3-4): 199-214.

12. Lin M, Lucas HC Jr, Shmueli G. Too big to fail: large samples and p-value problem. Inf Syst Res. 2013; 24: 906-917.

13. Ariano R, Berra D, Chiodini E, Ortolani V, Cremonte LG, Mazzarello MG, et al. Ragweed allergy: Pollen count and sensitization and allergy prevalence in two Italian allergy centers. Allergy Rhinol (Providence). 2015; 6(3): 177-83.

14. Thibaudon M, Hamberger C, Guilloux L, Massot R. Ragweed pollen in France: origin, diffusion, exposure. Eur Ann Allergy Clin Immunol. 2010; 42(6): 209-15.

15. Ridolo E, Albertini R, Giordano D, Soliani L, Usberti I, Dall'Aglio PP. Airborne pollen concentrations and the incidence of allergic asthma and rhinoconjunctivitis in northern Italy from 1992 to 2003. Int Arch Allergy Immunol. 2007; 142(2): 151-57.

16. Crockett AJ, Alpers JH. A profile of respiratory symptoms in urban and rural South Australian school children. J Paediatr Child Health. 1992; 28(1): 36-42.

17. Majkowska-Wojciechowska B, Pełka J, Korzon L, Kozłowska A, Kaczała M, Jarzebska M, et al. Prevalence of allergy, patterns of allergic sensitization and allergy risk factors in rural and urban children. Allergy. 2007; 62(9): 1044-50.

18. Juhász A, Nagy Cs, Páldy A, Beale L. Development of a Deprivation Index and its relation to premature mortality due to diseases of circulatory system in Hungary,1998-2004. Soc Sci Med. 2010; 70(9): 342-9.

19. Gehring U, Pattenden S, Slachtova H, Antova T, Braun-Fahrländer C, Fabianova E, et al. Parental education and children's respiratory and allergic symptoms in the Pollution and the Young (PATY) study. Eur Respir J. 2006; 27(1): 95-107.

20. Bråbäck L, Breborowicz A, Dreborg S, Knutsson A, Pieklik H, Björkstén B. Atopic sensitization and respiratory symptoms among Polish and Swedish school children. Clin Exp Allergy. 1994; 24(9): 826-35.

21. von Mutius E, Fritzsch C, Weiland SK, Röll G, Magnussen H. Prevalence of asthma and allergic disorders among children in united Germany: a descriptive comparison. BMJ. 1992; 305(6866): 1395-9.

22. Krämer U, Oppermann H, Ranft U, Schäfer T, Ring J, Behrendt H. Differences in allergy trends between East and West Germany and possible explanations. Clin Exp Allergy. 2010; 40(2): 289-98.

23. McKeever TM, Lewis SA, Smith C, Collins J, Heatlie H, Frischer M, et al. Early exposure to infections and antibiotics and the incidence of allergic disease: a birth cohort study with the West Midlands General Practice Research Database. J Allergy Clin Immunol. 2002; 109(1):4 3-50.

24. Strachan DP, Taylor EM, Carpenter RG. Family structure, neonatal infection and hay fever in adolescence. Arch Dis Child. 1996; 74: 422-26.

25. Kuo CH, Kuo HF, Huang CH, Yang SN, Lee MS, Hung CH. Early life exposure to antibiotics and the risk of childhood allergic diseases: an update from the perspective of the hygiene hypothesis. J Microbiol Immunol Infect. 2013; 46(5): 320-29.

26. Farooqi IS, Hopkin JM. Early childhood infection and atopic disorder. Thorax 1998; 53(11): 927-32.

27. Kalliomäki M, Kirjavainen P, Eerola E, Kero P, Salminen S, Isolauri E. Distinct patterns of neonatal gut microflora in infants in whom atopy was and was not developing. J Allergy Clin Immunol. 2001; 107(1): 129-34.

28. Seo JH, Kim HY, Jung YH, Lee E, Yang SI, Yu HS, et al. Interactions between innate immunity genes and early-life risk factors in allergic rhinitis. Allergy Asthma Immunol Res. 2015; 7(3): 241-48.

29. Butland BK, Strachan DP, Lewis S, Bynner J, Butler N, Britton J. Investigation into the increase in hay fever and eczema at age 16 observed between the 1958 and 1970 British birth cohorts. BMJ. 1997; 315: 717-21.

30. Pistiner M, Gold DR, Abdulkerim H, Hoffman E, Celedón JC. Birth by cesarean section, allergic rhinitis, and allergic sensitization among children with a parental history of atopy. J Allergy Clin Immunol. 2008; 122(2): 274-79.

31. Lewis SA, Britton JR. Consistent effects of high socioeconomic status and low birth order, and the modifying effect of maternal smoking on the risk of allergic disease during childhood. Respir Med. 1998; 92: 1237-44.

32. Keil T, Lau S, Roll S, Grüber C, Nickel R, Niggemann B, et al. Maternal smoking increases risk of allergic sensitization and wheezing only in children with allergic predisposition: longitudinal analysis from birth to 10 years. Allergy. 2009; 64(3): 445-51.

33. Rudnai P, Varró MJ, Mácsik A, Tüske-Szabó E, Középesy S, Rudnai T, et al. Urban-rural differences in the prevalence of respiratory symptoms of school children in Hungary. Cent Eur J Occ Envir Med. 2014; 20(1-2): 67-78.

34. Pénard-Morand C, Raherison C, Charpin D, Kopferschmitt C, Lavaud F, Caillaud D, et al. Long-term exposure to close-proximity air pollution and asthma and allergies in urban children. Eur Respir J. 2010; 36(1): 33-40.

35. Takizawa H. Impact of air pollution on allergic diseases. Korean J Intern Med. 2011; 26(3): 262-73. 